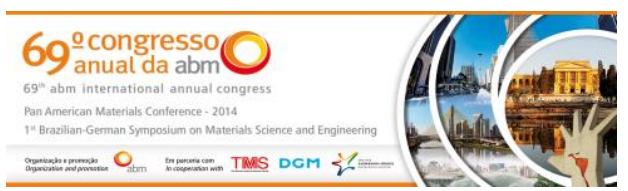

Tema: Gestão de manutenção

\title{
DESDOBRAMENTO ESTRATÉGICO PARA O PLANEJAMENTO DE MANUTENÇÃO EM USINAS DE PELOTIZAÇÃO*
}

\author{
Marcus Francisco Gonçalves Mesquita ${ }^{1}$ \\ Manoel Jose Pedrosa Filho² \\ Fabricio Dardengo Hupp ${ }^{3}$
}

\begin{abstract}
Resumo
As mudanças no plano estratégico de uma organização reverberam por todos os seus setores, gerando demandas de alinhamento estratégico. Entre estes setores estão os de planejamento e programação da manutenção. O presente estudo de caso descreve uma iniciativa de alinhamento estratégico realizada pela equipe de planejamento de manutenção da unidade Ubu da Samarco Mineração S/A, uma empresa de mineração e pelotização de minério de ferro, localizada no estado do Espírito Santo. A partir de uma revisão na estratégia corporativa foram derivados a missão, visão e valores da equipe. Esses por sua vez, serviram de base para uma revisão dos processos de trabalho e para a definição de ações de melhoria. Por fim foram estabelecidos indicadores para mensurar a realização da visão. Os resultados apresentados por esses indicadores comprovam que as equipes de planejamento podem obter e demonstrar resultados significativos através de técnicas elementares de planejamento estratégico.
\end{abstract}

Palavras-chave: Manutenção; Planejamento estratégico; Planejamento da manutenção.

\section{STRATEGIC PLANNING FOR THE DEPLOYMENT OF MAINTENANCE IN PLANTS PELLETIZING}

\section{Abstract}

Changes in organizations strategic plans reverberate through all of their sectors, creating strategic alignment demands. One of those sectors is maintenance planning and schedulling. This case study describes a strategic alignment initiative implemented by the maintenance planning team from Samarco Mineração, an iron ore mining and pelletizing company from Espírito Santo, Brazil. After changes on the organization strategic plan, the maintenance planning team developed mission, vision and values, which were used to review the work process, and to propose improvement actions. Them, performance indicator were established to measure vision achievement. The significant results showed by the indicators demonstrate that maintenance planning teams can achieve and demonstrate significant results applying simple strategic planning techniques.

Keywords: Maintenance; Strategic planning; Maintenance planning.

1 Engenheiro Mecânico, Bacharel, Planejador de manutenção, Departamento de planejamento de manutenção, Samarco Mineração S/A, Anchieta, ES, Brasil.

2 Engenheiro Mecânico, Bacharel, Chefe de equipe planejamento de manutenção, Departamento de planejamento de manutenção, Samarco Mineração S/A, Anchieta, ES, Brasil.

3 Engenheiro Mecânico, Bacharel, Engenheiro de manutenção especialista, Gerência de manutenção, Samarco Mineração S/A, Anchieta, ES, Brasil.

\footnotetext{
* Contribuição técnica ao $69^{\circ}$ Congresso Anual da ABM - Internacional e ao 14ํㅡㄹ ENEMET - Encontro Nacional de Estudantes de Engenharia Metalúrgica, de Materiais e de Minas, 21 a 25 de julho de 2014, São Paulo, SP, Brasil.
} 


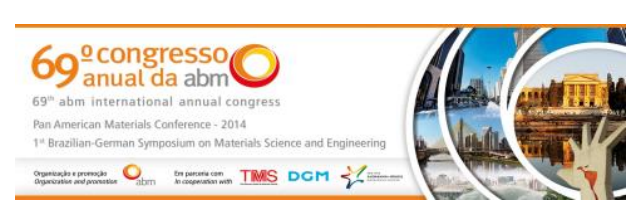

\section{INTRODUÇÃO}

O seguinte trabalho foi elaborado na Samarco Mineração, empresa brasileira de mineração, de capital fechado, controlada em partes iguais por dois acionistas: BHP Billiton Brasil Ltda. e Vale S/A, sendo a oitava maior exportadora do país (Departamento de Comércio Exterior do Ministério do Desenvolvimento, Indústria e Comércio Exterior - Janeiro de 2013) e a segunda maior fornecedora de pelotas de minério de ferro no mercado transoceânico. O principal produto da Samarco são pelotas de minério de ferro produzidas a partir da transformação de minerais de baixo teor em um produto nobre, de alto valor agregado, e comercializado para a indústria siderúrgica mundial.

Devido às incertezas quanto ao preço do minério de ferro, o aumento da pressão sobre os custos e a disponibilidade de insumos e recursos naturais, a Samarco reestruturou sua missão, visão e valores e atualizou sua estratégia para adequar-se ao novo cenário. Com objetivo de trabalhar de maneira integrada a esta visão, a equipe de planejamento de manutenção da unidade de Ubu desdobrou a estratégia, criando a missão, visão e valores do planejamento. Na visão de Murthy [1] a gestão da manutenção deve ser estratégica e a mesma tem uma função vital para a sobrevivência e sucesso das organizações.
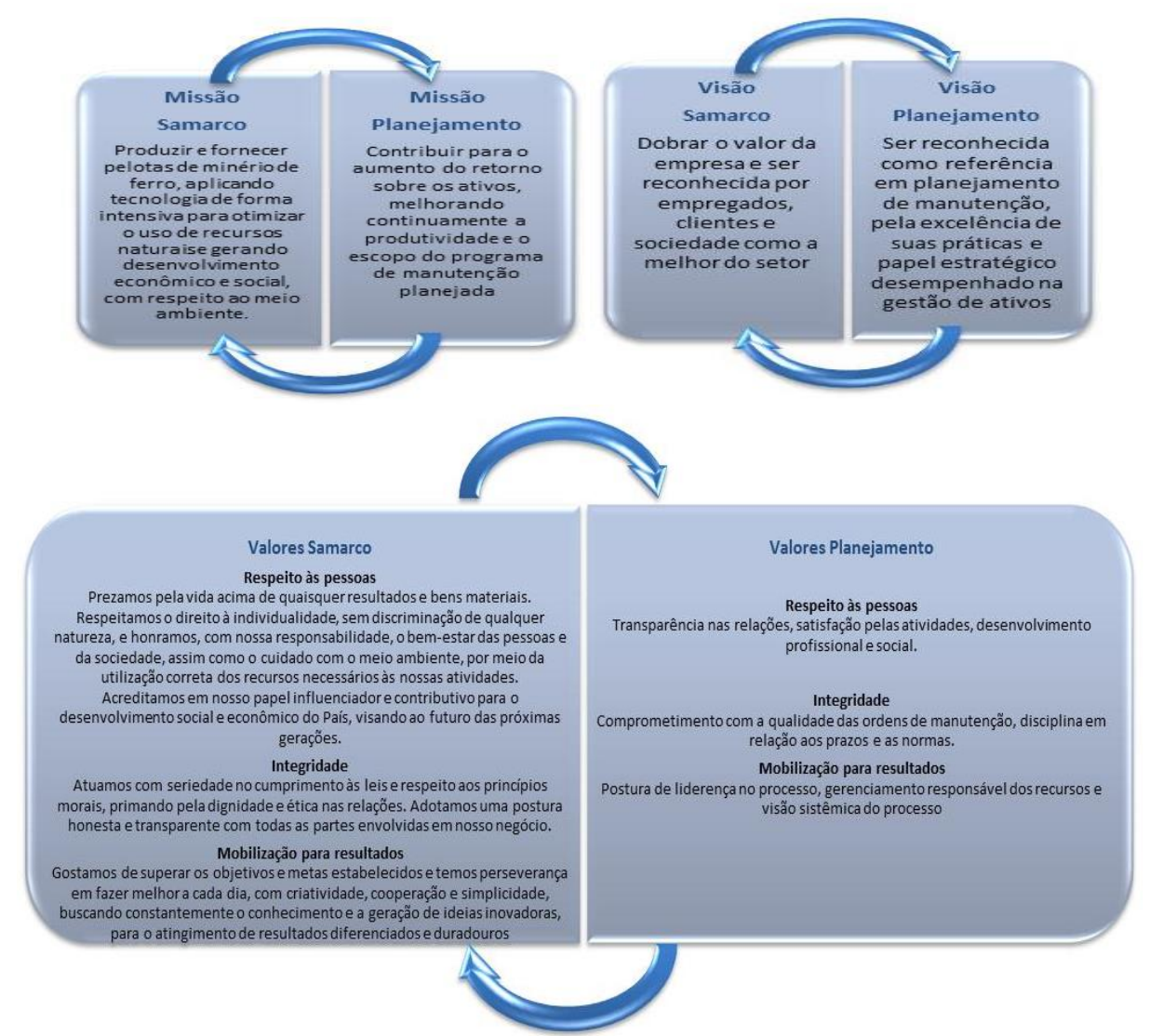

Figura 1. Missão, visão e valores da Samarco e do Planejamento.

O planejamento da manutenção deve fazer parte do desdobramento do planejamento estratégico global da empresa, onde este tem como objetivo orientar as ações e resposta de uma empresa às demandas do ambiente em que está inserida [2].

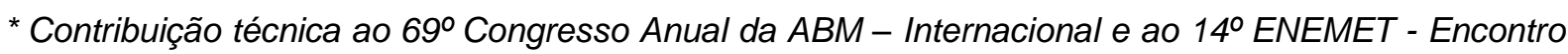
Nacional de Estudantes de Engenharia Metalúrgica, de Materiais e de Minas, 21 a 25 de julho de 2014, São Paulo, SP, Brasil.
} 


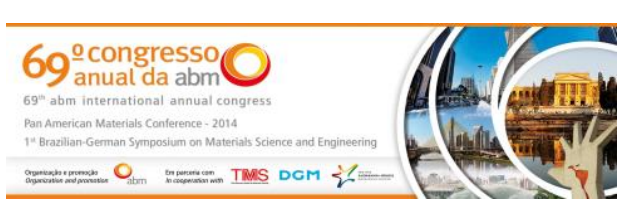

O primeiro passo foi o mapeamento das entregas necessárias para obter a excelência em planejamento e a criação de um plano de ação que nos permita alcançar tais objetivos. Devido ao planejamento estratégico ser realizado em âmbito organizacional, foi definido uma nova estrutura do processo.

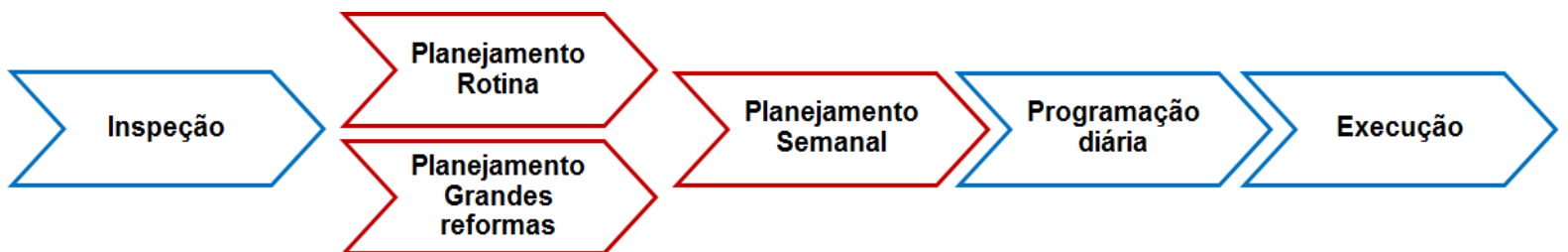

Figura 2. Processo de planejamento.

O principal papel do planejamento é otimizar os recursos de manutenção, buscando o melhor custo benefício e o aumento da produtividade da mão de obra. Para obter sucesso nessa entrega é necessário o máximo aproveitamento das paradas dos ativos, agrupando as especialidades e recursos.

O agrupamento das especialidades se dá pela integração dos serviços das equipes interessadas, sendo elas, mecânica, elétrica e instrumentação. Essa integração se faz necessária para reduzir o tempo de parada do ativo, momento de interrupção do funcionamento da máquina para executar as atividades de manutenção, aumentando a disponibilidade das máquinas e consequentemente a produção.

Por esses motivos, a equipe foi estruturada em três setores: planejamento de rotina, planejamento semanal e planejamento de paradas (grandes intervenções).

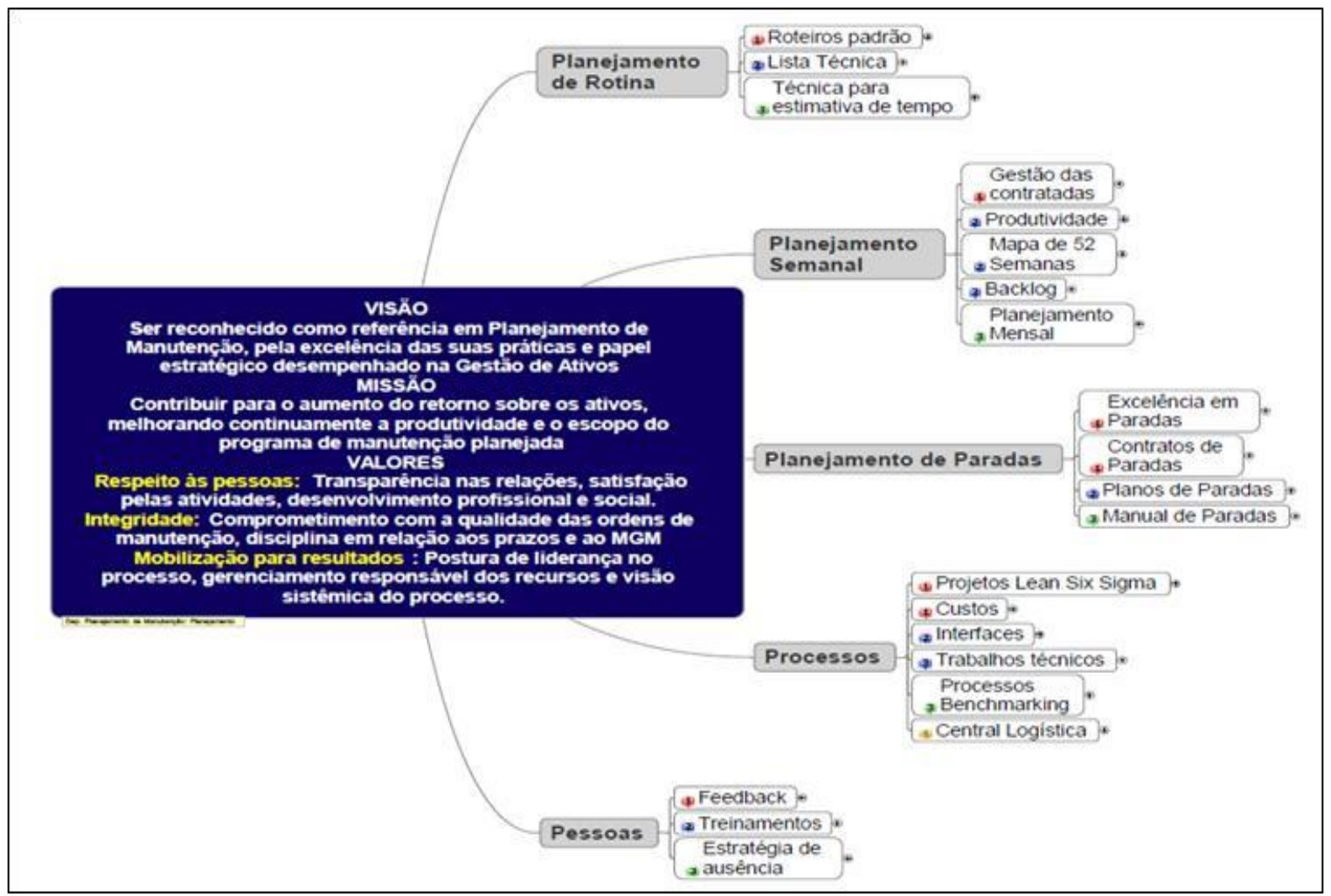

Figura 3. Desdobramento estratégico do planejamento.

O planejamento de rotina tem como função elaborar as ordens de serviços, inserindo os recursos necessários, sendo eles, a mão de obra, tempo de intervenção, os

* Contribuição técnica ao 69 Congresso Anual da ABM - Internacional e ao 14ํN ENEMET - Encontro Nacional de Estudantes de Engenharia Metalúrgica, de Materiais e de Minas, 21 a 25 de julho de 2014, São Paulo, SP, Brasil. 


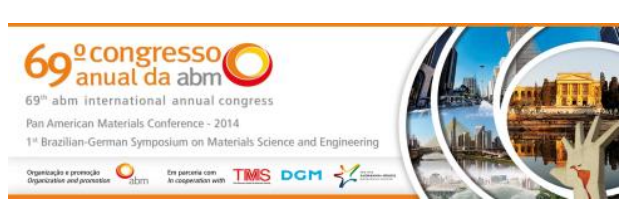

materiais, as ferramentas e os equipamentos de apoio. Para Nyman [3], trabalhos bem planejados, devidamente programados e comunicados com eficácia realizam mais, com maior eficiência e a um custo menor.

Para obter um feedback contínuo do tempo das atividade, a equipe de planejamento utiliza técnicas de estimativas de tempo, realimentando quando necessário as ordens de serviço. Um dos pontos mais importantes na elaboração das ordens de serviço é a solicitação dos materiais, para evitar desvios é necessário criar e manter uma lista técnica atualizada, com informações dos equipamentos e seus componentes.

O planejamento semanal foi criado devido à necessidade de construção de uma interface com a produção da Samarco, no intuito de alinhar as paradas de máquinas e agrupar as especialidades envolvidas. Para executar essa interface foi elaborada a reunião de programação semanal, que tem a finalidade de efetuar acordo de paradas programadas com a produção e as áreas interessadas em função das demandas.

A principal função do planejamento semanal é criar e manter atualizado um mapa de 52 semanas, que se resume a uma programação de paradas de máquinas seguindo as premissas de custos, frequência dos planos de manutenção, capacidade de mão de obra, metas de disponibilidade e campanhas de produção.

A formação da equipe de planejamento de paradas fez-se necessária pela busca de padrões de excelência nas grandes intervenções, como exemplo, as paradas das usinas (unidades industriais de pelotização), que transformam o minério em pelotas. A parada de usina é um projeto crítico da manutenção que ocorre uma vez ao ano, com duração média de sete dias e escopos de serviço variados.

A equipe responde pelo cumprimento do plano mestre, baseado na metodologia TFEL (Turnaround Front End Loading) processo que são estabelecidas fases consecutivas para um projeto, e é auditada pelo IPA (Independent Project Analysis).

A IPA (Independent Project Analysis) é uma empresa líder em pesquisa e consultoria em gestão de projetos e paradas e já realizou centenas de estudos de pesquisa que relacionam práticas de projeto e/ou de parada utilizando bancos e dados de mais de 16.000 projetos de capital e 400 paradas.

\section{MATERIAIS E MÉTODOS}

O presente trabalho descreve um estudo de caso na empresa Samarco Mineração S/A, envolvendo a equipe de planejamento de manutenção da unidade de Ubu no ano de 2013. Para Cobra [4], um estudo de caso pode ser conceituado como a descrição de uma situação ou problema. Já Haguette [5] define o estudo de caso, como sendo a análise minuciosa e objetiva de uma situação real que foi investigada.

Durante o estudo, os processos críticos foram mapeados para garantir um melhor desempenho das equipes e a maior disponibilidade operacional dos ativos.

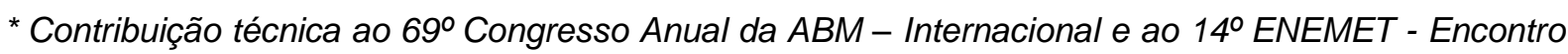
Nacional de Estudantes de Engenharia Metalúrgica, de Materiais e de Minas, 21 a 25 de julho de 2014, São Paulo, SP, Brasil.
} 

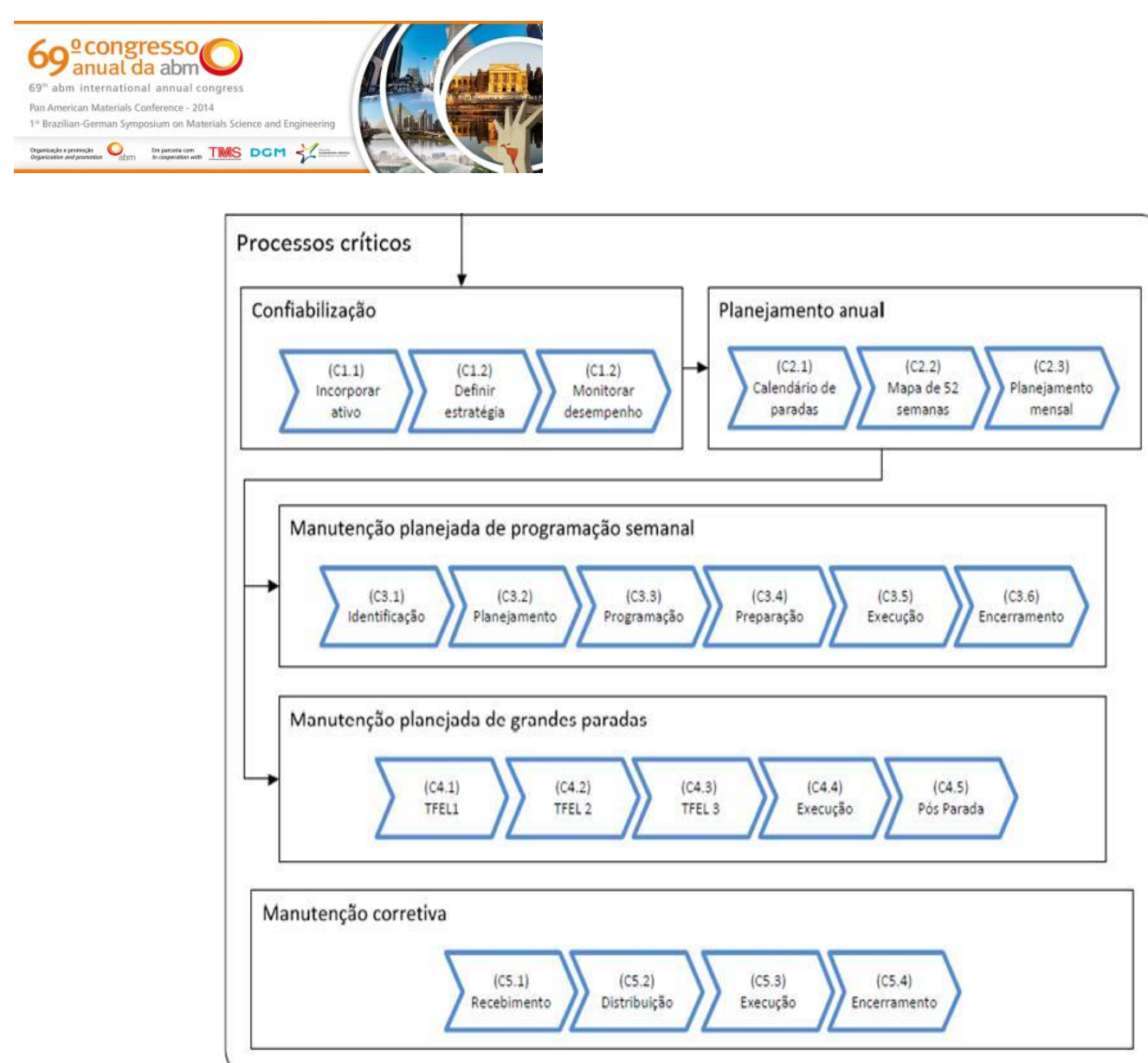

Figura 4. Processo de trabalho do planejamento de manutenção.

Após o mapeamento, fez-se necessário a análise crítica de cada processo, sendo possível a tomada de decisões das atividades inseridas no desdobramento estratégico para o planejamento. Para cada setor foi elaborado um plano de ação constando o "o quê" (what) e o "como" (how) para alcançar as metas propostas pelo BSC (Balanced Scored Card) da manutenção, desenvolvido previamente em um desdobramento estratégico conduzido no nível da Gerência de Manutenção da unidade de Ubu.

\subsection{Planejamento de Rotina}

Para o planejamento de rotina foram priorizadas três atividades críticas: roteiro padrão, lista técnica e estimativa de tempo. Devido ao número expressivo de ativos, o processo de roteiro padrão foi elaborado apenas para os ativos de criticidade $A$, do qual, representam riscos operacionais e/ou de saúde e segurança. Segundo Nascif [6] 80\% das consequências advêm de $20 \%$ das causas.

Os roteiros padrões são instruções técnicas de como executar os serviços de manutenção e garantem que as atividades sejam realizadas de forma padronizada e com qualidade, evitando retrabalhos.

A lista técnica é uma ferramenta que possibilita o usuário a inserir a lista de componentes atrelados ao código da máquina. A lista técnica é uma das principais ferramentas para garantir a aquisição correta dos materiais, evitando falhas por ausência ou divergências nas ordens de manutenção.

A estimativa de tempo são técnicas que permitem otimizar os recursos de mão de obra especializada, aumentando a produtividade das equipes de manutenção e reduzindo o tempo de parada das máquinas. Dentre as técnicas de estimativa de tempo utilizada no estudo, está à medição de produtividade, um constante monitoramento da mão de obra com intuito de ajustar a capacidade produtiva.

\footnotetext{
* Contribuição técnica ao $69^{\circ}$ Congresso Anual da ABM - Internacional e ao 14ํㅡㄹ ENEMET - Encontro Nacional de Estudantes de Engenharia Metalúrgica, de Materiais e de Minas, 21 a 25 de julho de 2014, São Paulo, SP, Brasil.
} 


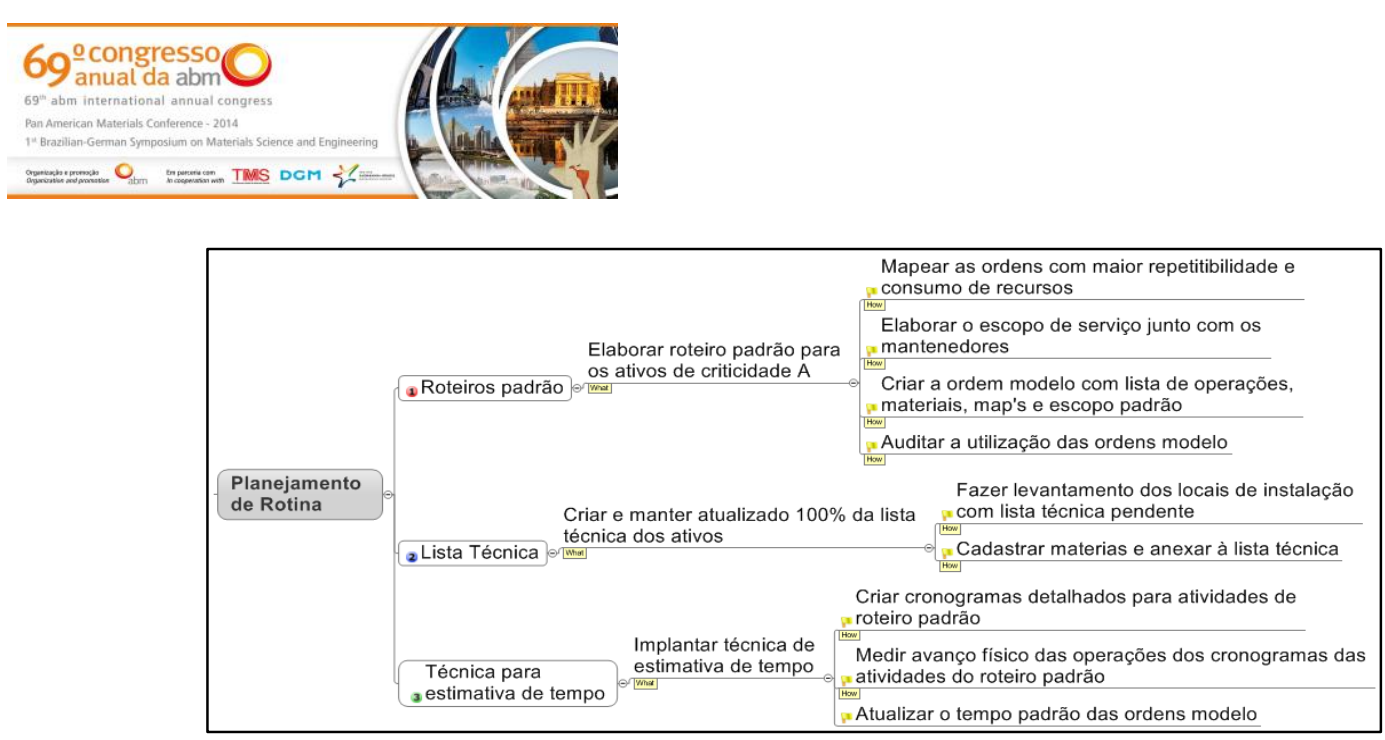

Figura 5. Desdobramento estratégico - Planejamento de rotina.

\subsection{Planejamento Semanal}

A base do planejamento semanal é o mapa de 52 semanas, com a definição das programações de paradas de máquinas. A partir do mapa é feito o desdobramento para o planejamento semanal, que contempla as atividades programadas e os recursos necessários. Para Kardec e Xavier [7] as tarefas de manutenção podem ser planejadas em intervalos de tempo pré-estabelecidos ou pelo monitoramento da condição de operação de um determinado equipamento.

Para aprimorar o mapa de 52 semanas é necessário implantar em paralelo o controle do backlog ("Fila" de atividades planejadas), a revisão sistêmica dos planos de manutenção e a medição de produtividade das equipes.

Um dos fatores para alcançar a excelência em planejamento é o engajamento de todos os stakeholders na nova missão, visão e valores, para isso, a gestão das contratadas foi implantada, garantindo o alinhamento do planejamento de manutenção da Samarco e das contratadas.

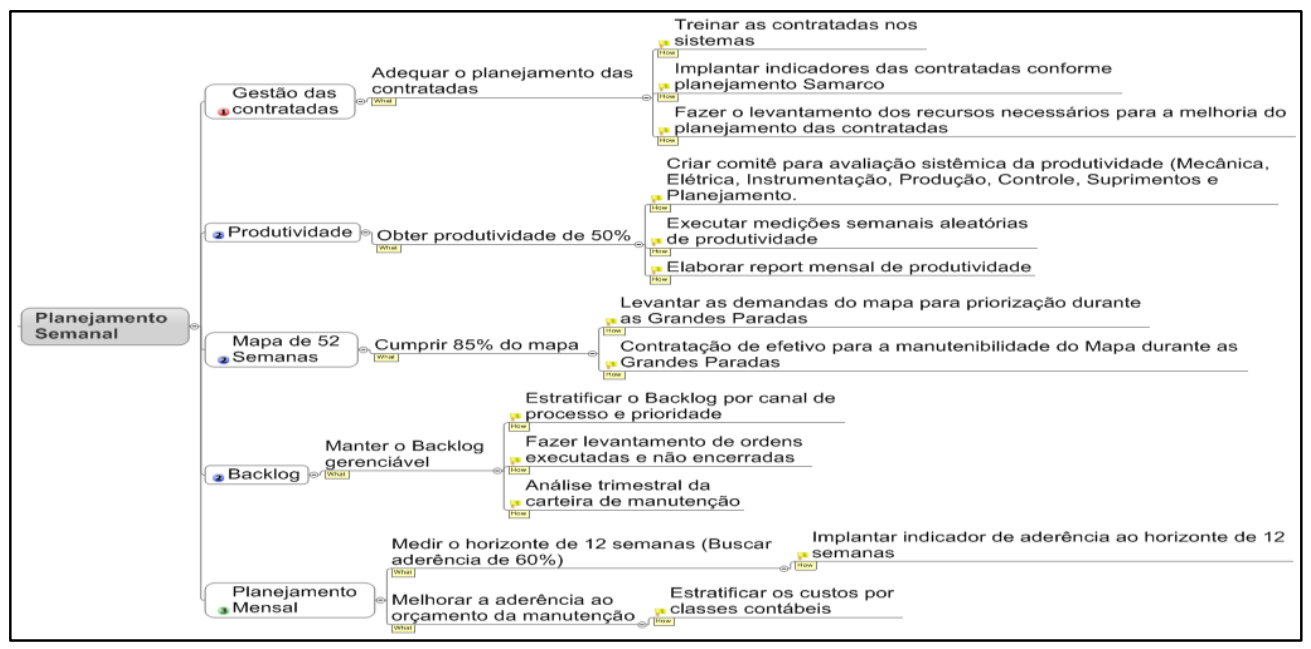

Figura 6. Desdobramento estratégico - Planejamento semanal

\subsection{Planejamento de Paradas}

As paradas de usinas representam um evento estratégico para a manutenção, habilitando a planta para operar sem interrupção de produção por um período de até doze meses.

\footnotetext{
* Contribuição técnica ao $69^{\circ}$ Congresso Anual da ABM - Internacional e ao 14ํㅡㄹ ENEMET - Encontro Nacional de Estudantes de Engenharia Metalúrgica, de Materiais e de Minas, 21 a 25 de julho de 2014, São Paulo, SP, Brasil.
} 


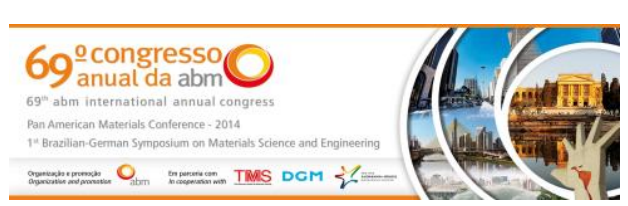

A abordagem do desdobramento para o planejamento de paradas resultou na implantação da metodologia TFEL (Turnaround Front End Loading) e na utilização das práticas PMBOK (Project Management Body of Knowledge).

A metodologia TFEL (Turnaround Front End Loading), é um processo que são estabelecidas fases consecutivas para um projeto, o qual só poderá passar para a fase seguinte se for aprovado. As fases são avaliadas por um comitê, composto por integrantes da gerência da manutenção, e são compostas por elementos do índice TFEL (Turnaround Front End Loading).

Os elementos que compõem o índice TFEL (Turnaround Front End Loading) são definição do escopo da parada (Objetivo, Conformidade dos Stakeholders, Lista de tarefas e Controle) na estratégia de execução (papéis e responsabilidades, Contratação, Cronograma e Análise de riscos) e o status do planejamento (Data fixada, disponibilidade de recursos, entrega dos materiais, procedimentos de operação e planos detalhados).

O PMBOK (Project Management Body of Knowledge) é destinado ao gerenciamento de projetos e pode ser definido tecnicamente como sendo uma norma reconhecida para a profissão de gerenciamento de projetos. É um padrão que identifica e nomeiam os processos, técnicas, regras e métodos para o gerenciamento de projetos.

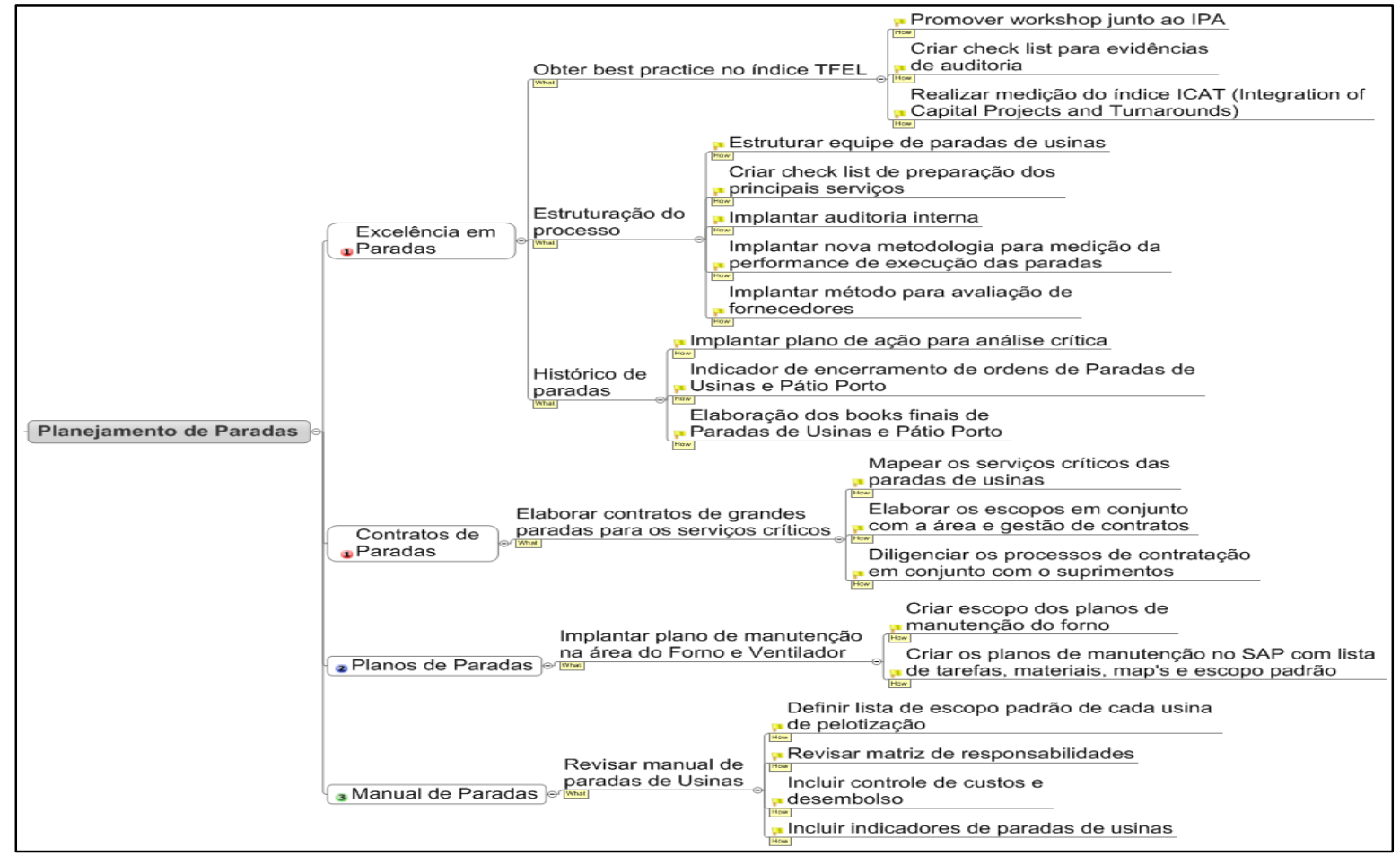

Figura 7. Desdobramento estratégico - Planejamento de paradas.

\subsection{Processos}

Para o planejamento de manutenção alcançar um nível de excelência é preciso definir as interfaces críticas para o processo, alinhando as entregas fundamentais de cada área envolvida. As interfaces mapeadas no estudo são: Suprimentos, engenharia de manutenção, produção, inspeção, execução, serviços contratados e engenharia de projetos.

\footnotetext{
* Contribuição técnica ao $69^{\circ}$ Congresso Anual da ABM - Internacional e ao 14ํㅡㄹ ENEMET - Encontro Nacional de Estudantes de Engenharia Metalúrgica, de Materiais e de Minas, 21 a 25 de julho de 2014, São Paulo, SP, Brasil.
} 


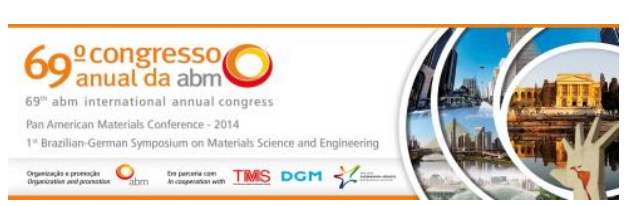

$\mathrm{Na}$ área de suprimentos, é necessário manter todos os ativos criticados e o sistema de aquisição de materiais atualizado. A engenharia de manutenção define os planos de manutenção e a engenharia de projetos, defini as atividades dos projetos de capital, identificando às interferências e o follow-up das alterações executadas.

Um dos maiores desafios no desdobramento é a gestão integrada dos custos, sendo necessária a definição dos representantes de cada setor ou gerência e a criação dos procedimentos de medição e envio dos reports com frequências estabelecidas que forneçam em tempo suficiente as informações para tomadas de decisão.

Dentro dos processos devem-se mapear os projetos de melhoria contínua. Como ferramentas de melhorias a Samarco adotou programas como o Lean Six Sigma, o Kaizen e trabalhos técnicos que possam trazer retornos financeiros ou melhorias para a organização, além de buscar benchmarks e estudar metodologias usadas em empresas similares. O programa Lean Six Sigma é resultante da integração entre o Seis Sigma e o Lean Manufacturing, por meio da incorporação dos pontos fortes de cada um deles. O Seis Sigma tem como objetivo aumentar expressivamente a performance e a lucratividade das empresa e o Lean Manufacturing, por sua vez, é uma iniciativa que busca eliminar desperdícios, isto é, excluir o que não tem valor para o cliente.

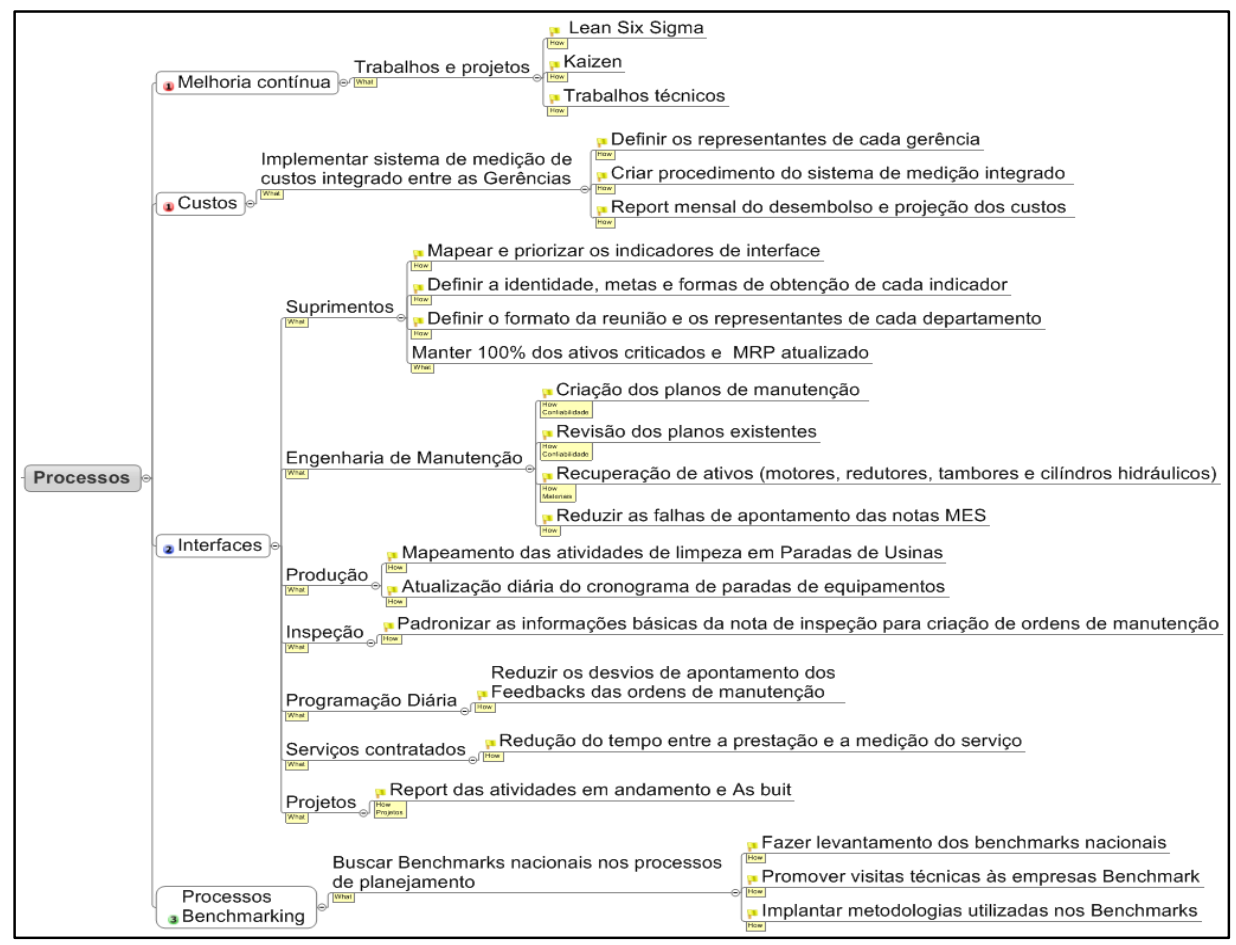

Figura 8. Desdobramento estratégico - Processo

\subsection{Pessoas}

O processo de desenvolvimento de pessoas não significa apenas oferecer capacitação para que possam realizar seus trabalhos de forma mais produtiva. Significa também, identificar os perfis adequados para cada posição, corrigir os gaps de formação técnica e encorajar a equipe a assumir postura de liderança nos processos que atuam.

A mobilização para os resultados é um dos valores da Samarco, e por isso, é imprescindível um programa de treinamento associado às necessidades estratégicas

\footnotetext{
* Contribuição técnica ao $69^{\circ}$ Congresso Anual da ABM - Internacional e ao 14ํㅡㄹ ENEMET - Encontro Nacional de Estudantes de Engenharia Metalúrgica, de Materiais e de Minas, 21 a 25 de julho de 2014, São Paulo, SP, Brasil.
} 


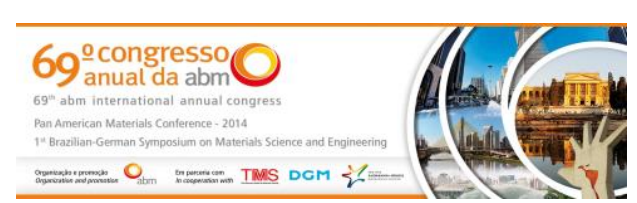

da organização. Para Davel e Vergara [8], investir no desenvolvimento de pessoas é investir na qualidade dos produtos e serviços, é atender melhor aos clientes e ampliar o faturamento.

Como parte fundamental do processo de desenvolvimento de pessoas a Samarco realiza um ciclo de avaliação de desempenho, denominado Feedback, com intuito de orientar os colaboradores a apresentarem um comportamento e desempenho apropriados a missão, visão e valores da empresa.

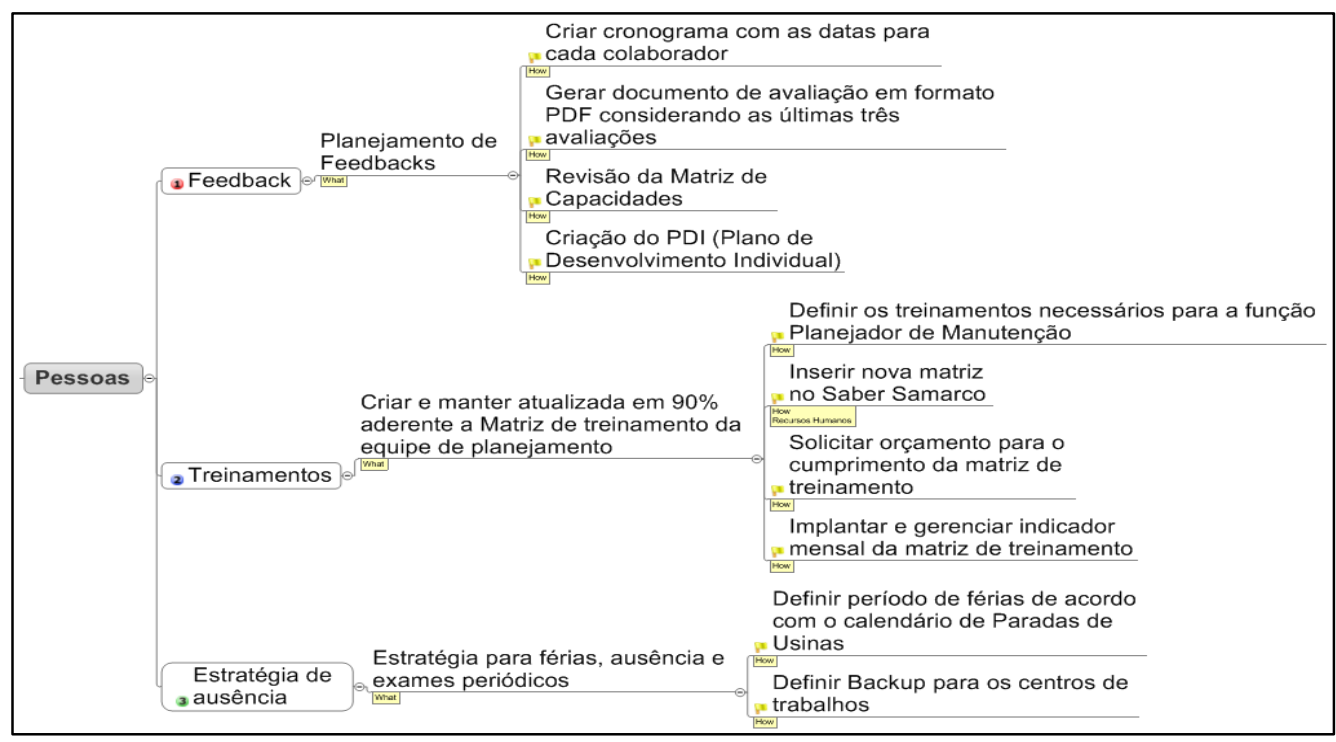

Figura 9. Desdobramento estratégico - Pessoas.

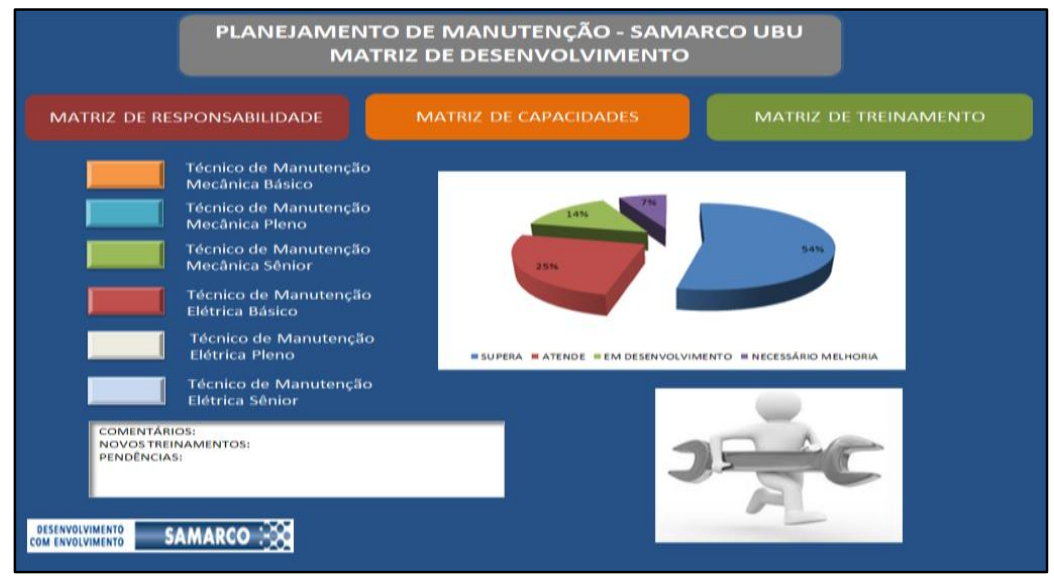

Figura 10. Matriz de desenvolvimento.

\subsection{Indicadores e Auditorias}

A sustentabilidade do projeto é feita através de indicadores de planejamento aliada aos processos de auditorias internas. Todos os indicadores foram elaborados com 0 intuito de analisar o desempenho do planejamento e têm como propósito os seguintes itens: controle, previsibilidade, estimativa, suporte à tomada de decisão, identificação e solução de problemas e monitoramento da implantação da estratégia. Um dos pontos mais importantes é listar, padronizar e documentar os indicadores e suas formas de obtenção. As metas devem ser estabelecidas de acordo com o BSC e visando sempre, os inputs e outputs de planejamento.

\footnotetext{
* Contribuição técnica ao 69ำ Congresso Anual da ABM - Internacional e ao 14ํㅡㄹ ENEMET - Encontro Nacional de Estudantes de Engenharia Metalúrgica, de Materiais e de Minas, 21 a 25 de julho de 2014, São Paulo, SP, Brasil.
} 


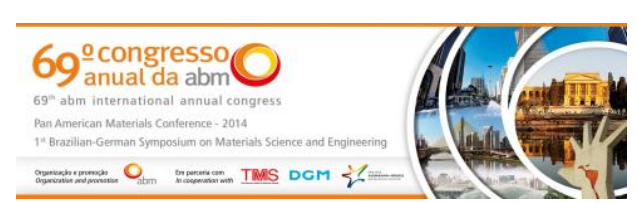

Mostafa [9] a manutenção deve ser estratégica e controlada por indicadores os quais devem refletir os padrões desejáveis de performance dos equipamentos.

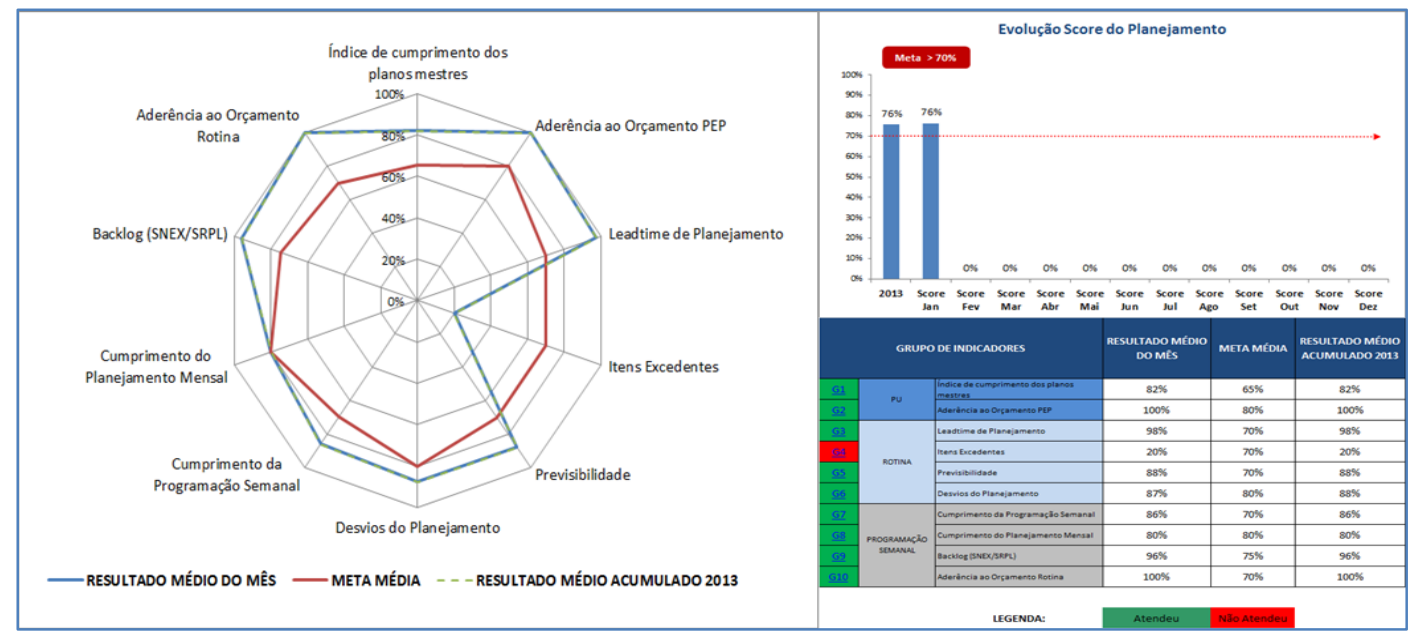

Figura 11. Radar de indicadores.

\section{RESULTADOS E DISCUSSÃO}

Através do desdobramento estratégico para o planejamento de manutenção, é possível avaliar as entradas e saídas do processo e maximizar os resultados, implantando planos de desenvolvimento de pessoas e processos que podem ser estabelecidos em etapas anuais, mensais e semanais.

$\mathrm{Na}$ etapa anual do plano de desenvolvimento é contemplado os novos projetos, capacitação de pessoas, recuperação de ativos e grandes reformas. Na etapa mensal, estão as preventivas da manutenção, aquisições de sobressalentes (compra de materiais), contratações de serviços, previsões de custos, estratégia de produção e necessidade de mão de obra. Na etapa semanal, é abordada a aderência das paradas de máquinas, materiais disponíveis, mão de obra especializada, interface com suprimentos, ordens de serviço planejados e o fluxo de desembolso.

Em relação ao objetivo central deste trabalho, os resultados obtidos foram satisfatórios em diversos fatores, como o maior envolvimento e integração dos stakeholders, a capacitação das equipes, o alinhamento em relação a missão, visão e valores da empresa e do planejamento e o alcançe das metas dos indicadores.

\footnotetext{
* Contribuição técnica ao 69ำ Congresso Anual da ABM - Internacional e ao 14ํㅡㄹ ENEMET - Encontro Nacional de Estudantes de Engenharia Metalúrgica, de Materiais e de Minas, 21 a 25 de julho de 2014, São Paulo, SP, Brasil.
} 


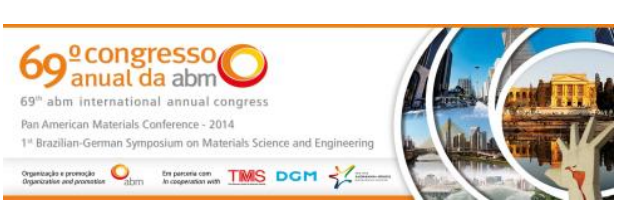

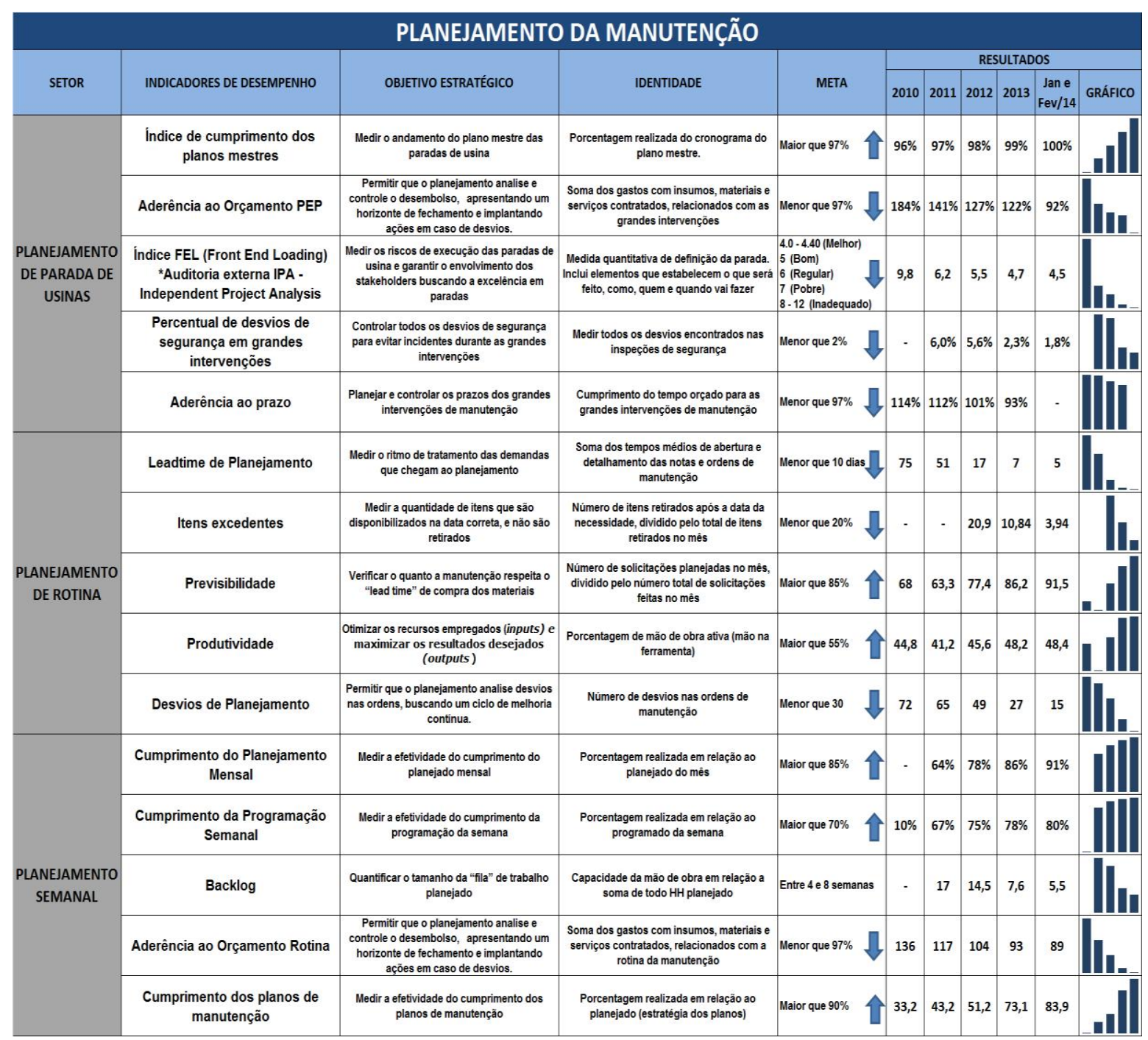

Figura 12. Resultados do desdobramento estratégico.

\section{CONCLUSÃo}

O objetivo principal deste trabalho foi propor um modelo de desdobramento estratégico para o planejamento de manutenção e avaliar o desempenho dos planos escolhidos durante o processo, com a finalidade de atender ao novo cenário da organização.

O trabalho foi desenvolvido com aplicações práticas na empresa Samarco Mineração S/A, com a participação do planejamento de manutenção e as áreas de interface. Por parte da empresa foi verificado que o desdobramento estratégico contribuiu para o direcionamento das ações.

$\mathrm{Na}$ avaliação geral, pode-se concluir que as equipes de planejamento de manutenção nas organizações podem obter resultados significativos utilizando técnicas e metodologias elementares de planejamento estratégico. Entre os resultados estão o maior envolvimento e a adequação dos Stakeholders quanto aos aspectos de planejamento, segurança, saúde e meio ambiente, a capacitação das equipes, a melhoria da interface com os setores da organização, a gestão integrada de custos e o alcance das metas dos principais indicadores de planejamento, incluindo, segurança, custos, prazo, produtividade, backlog e lead time.

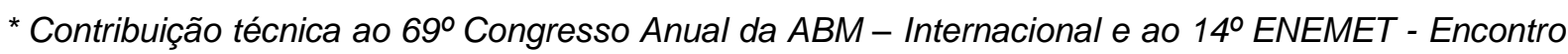
Nacional de Estudantes de Engenharia Metalúrgica, de Materiais e de Minas, 21 a 25 de julho de 2014, São Paulo, SP, Brasil.
} 
